\title{
Integrated chemical and biological assessment of contaminant impacts in selected european coastal and offshore marine areas
}

Hylland Ketil ${ }^{1,}{ }^{*}$, Robinson Craig D. ${ }^{2}$, Burgeot Thierry ${ }^{3}$, Martínez-Gómez Concepción ${ }^{4}$, Lang Thomas ${ }^{5}$, Svavarsson Jörundur ${ }^{6}$, Thain John E. ${ }^{7}$, Vethaak A. Dick ${ }^{8,9}$, Gubbins Mattew J. ${ }^{2}$

${ }^{1}$ Department of Biosciences, University of Oslo, PO Box 1066, Blindern, N-0316, Oslo, Norway

2 Marine Scotland Science, Marine Laboratory, 375 Victoria Road, Aberdeen, AB11 9DB, UK

${ }^{3}$ IFREMER, Laboratory of Ecotoxicology, Rue de I'lle d'Yeu, B.P. 21105, 44311, Nantes Cédex 03, France

${ }^{4}$ Instituto Español de Oceanografía (IEO), Oceanographic Centre of Murcia, Varadero 1, PO BOX 22, 30740, San Pedro del Pinatar (Murcia), Spain

${ }^{5}$ Thünen Institute of Fisheries Ecology, Deichstr. 12, 27472, Cuxhaven, Germany

${ }^{6}$ University of Iceland, Askja - Natural Science Building, Sturlugata 7, 101, Reykjavík, Iceland

${ }^{7}$ Cefas Weymouth Laboratory, Barrack Road, The Nothe, Weymouth, Dorset, DT4 8UB, UK

${ }^{8}$ Deltares, Marine and Coastal Systems, P.O. Box 177, 2600, MH Delft, The Netherlands

${ }^{9}$ VU University Amsterdam, Amsterdam Global Change Institute, Institute for Environmental Studies, De Boelelaan 1085, 1081 HV Amsterdam, The Netherlands

${ }^{*}$ Corresponding author : Ketil Hylland, email address : ketilhy@ibv.uio.no

\begin{abstract}
:
This paper reports a full assessment of results from ICON, an international workshop on marine integrated contaminant monitoring, encompassing different matrices (sediment, fish, mussels, gastropods), areas (Iceland, North Sea, Baltic, Wadden Sea, Seine estuary and the western Mediterranean) and endpoints (chemical analyses, biological effects).

ICON has demonstrated the use of a framework for integrated contaminant assessment on European coastal and offshore areas. The assessment showed that chemical contamination did not always correspond with biological effects, indicating that both are required. The framework can be used to develop assessments for EU directives. If a 95\% target were to be used as a regional indicator of MSFD GES, Iceland and offshore North Sea would achieve the target using the ICON dataset, but inshore North Sea, Baltic and Spanish Mediterranean regions would fail.
\end{abstract}




\section{Highlights}

- A framework for integrated assessment of contaminant impacts in coastal and offshore areas has been developed and demonstrated. The assessment clearly shows why it is necessary to include both chemical analyses and biological effects in an assessment of contaminant impacts. Only two of the areas, Iceland and offshore North Sea, would be classified as having "Good Environmental Status" should MSFD criteria be used.

Keywords : ICON, Contaminants, European seas, Biological effects, Assessment 
22 Thousands of tonnes of waste are released into European seas every minute, containing chemicals that have the potential to accumulate in marine organisms and/or affect their health. As discussed in Borja et al. (2010), it is crucial in this context to have a clear understanding of how it can be determined whether organisms or populations in an area are affected by pollution and if so, the extent to which they are impacted. With regards to chemicals, this implies quantifying chemical-specific effects on marine organisms or processes. In addition to a required knowledge of effects, there are reasons why it may also useful to have information about concentrations of chemicals in organisms or abiotic matrices: (i) to link observed effects to specific chemicals for regulatory purposes, (ii) to ensure concentrations are not above limits set for human consumption, and finally (iii) to document the presence of chemicals that may or may not cause effects. As support for effects, it is the exposure of organisms to chemicals that matters. For persistent bioaccumulating substances, exposure can be estimated through measuring the concentration of chemicals or their metabolites in the tissues of the target organism (e.g. Hylland et al., 2009) or in other matrices such as passive samplers (Utvik \& Gärtner, 2006), sediments or non-target organisms in the same habitat, e.g. blue mussels. Some polluting chemicals may however be quickly degraded or present at concentrations below the detection limit of routine chemical analyses, but still cause impacts, e.g. many endocrine disrupting substances, organophosphate pesticides and pharmaceuticals. In this case, biological responses will be the most sensitive method by which to detect their presence, e.g. through the inhibition of acetylcholinesterase as a result of organophosphate exposure (Bocquené et al., 1993) or increased plasma concentrations of vitellogenin in juvenile fish as a result of oestrogen exposure (Allen et al., 1999). To understand the possible environmental consequences and regulate inputs of contaminating chemicals, we therefore need to know both the concentrations of contaminants in appropriate matrices as well as how they affect organisms. The two types of measurements, chemical and biological, should ideally be combined in an integrated assessment (cf. Davies \& Vethaak, 2012). Any monitoring programme underpinning such an assessment will however produce a very extensive and complex data matrix, which will require some sort of aggregation procedure prior to being used for regulatory decisions. Such aggregation procedures are generally termed "indicators", 
aggregate or combine chemical analyses (see e.g. OSPAR, 2010) or biological responses, e.g. the health assessment index, HAI (Adams et al., 1993), biological assessment index, BAI (Broeg et al., 2005), an expert system (Viarengo et al., 2000; Dagnino et al., 2007), the integrated biological response, IBR (Devin et al., 2014), the biomarker response index (BRI) (Hagger at al., 2008) or the integrative biomarker Index, IBI (Marigómez et al., 2013). In addition, there are some practical examples of integrating or combining chemical analyses and biological responses, such as in the UK Fullmonti project, including chemical analyses, benthic community status and fish health (described in Thain et al., 2008) or by using a weight-of-evidence approach (see e.g. Chapman et al., 2002). In some national programmes, the interpretation of fish health is aided by taking account of contaminant levels in addition to confounding factors such as size and gender, and environmental factors such as temperature and season (see e.g. Sandström et al., 2005; Hylland et al., 2008, 2009; Vethaak et al., 2008). The main difference between the framework used here (described in Vethaak et al., this issue-a) and other indices is that the current framework is based on internationally agreed threshold criteria for biological responses and tissue residues of chemicals, identifying responses above background, responses that indicate probable impacts at the population level and concentration of chemicals above thresholds (see Robinson et al., this issue). In addition, the framework includes more matrices than most other indices and is flexible in the species included, as long as criteria exist for core methods.

Over the last decade, Europe has implemented two directives that largely direct the management of the environmental conditions of coastal and offshore marine areas, the Water Framework Directive (WFD, 2000/60/EC) and Marine Strategy Framework Directive (MSFD, 2008/56/ EC). Particularly descriptor 8 of MSFD, 'Concentrations of contaminants are at levels not giving rise to pollution effects", is clearly relevant for the assessment described here for the ICON project (International workshop on marine integrated contaminant monitoring, see Hylland et al., this issue-a, for a full description). Using biological responses to provide the information required for descriptor 8 has been suggested in e.g. Bourlat et al. (2013), Giltrap et al. (2013), Hagger et al. (2008), Lehtonen et al. (2014) and Lyons et al. (2010). As outlined in Lyons et al. (2010), the framework described in Vethaak et al. (this issue-a) and applied to the ICON project will 
86

87

88

89

90

91

92

93

94

95

96

97

98

99

100

101

102

103

104

105

106

107

108

109

110

111 output a metric that can be used to determine Good Environmental Practice (GES) in MSFD.

The current paper reports on an integrated assessment of the results from the ICON (International workshop on marine integrated contaminant monitoring) project, using results reported in Burgeot et al. (this issue), Carney Almroth et al. (this issue), Hylland et al. (this issue-b), Kammann et al. (this issue), Lang et al. (this issue - a,b), Lyons et al. (this issue), Martinez-Gomez et al. (this issue $-a, b$ ), Robertson et al. (this issue), Vethaak et al. (this issue-b).

As described in Vethaak et al. (this issue-a), this indicator of status for each determinant can then be combined at different levels: matrix, site and region, and expressed with varying levels of aggregation to graphically represent the proportion of different types of determinants (or for each determinant, sites within a region) exceeding assessment criteria. Such an approach has several advantages: (i) the combination of data can be done for selected levels depending on the type of assessment required and the monitoring data available, (ii) the representation maintains all the original information and it is straightforward to identify determinants that exceed the assessment criteria, (iii) any stage of the assessment can be readily "unpacked" to a previous stage to identify either contaminant or effects measurements of potential concern or sites contributing to poor regional assessments (cf. Jennings et al., 2008). In contrast to some other integrating indicators, e.g. IBI and BRI, there is no weighing of the methods included in the current framework. The approach is based on the OSPAR regional assessment tool developed for contaminants (OSPAR, 2010). 
112

113

114

115

116

117

118

119

120

121

122

123

124

125

126

127

128

129

130

131

132

133

134

135

136

137

138

139

140

141

142

143

144

\section{Methods}

The assessment criteria used with chemical components of the framework were OSPAR Background Assessment Criteria (BACs) and Environmental Assessment Criteria (EACs) or EU Environmental Quality Standards (EQSs); EC food safety regulation limits were used where EACs or EQSs are not available (OSPAR, 2008). Food safety regulation limits are not necessarily protective for the environment. Assessment criteria for biological responses (biomarkers) were from Davies \& Vethaak (2012). Initial comparisons (step 1 below) would decide whether the concentration or response for any species or matrix at any site was less than BAC, between the BAC and EAC, or above EAC. As described in detail in Hylland et al. (this volume - a) and Vethaak et al. (this volume - a), biological responses were grouped in either "exposure" or "effect", subject to whether there is available data showing adverse effects corresponding to that particular response.

The sites included in the ICON project are described in Hylland et al. (this issue - a). They comprised sites from the Mediterranean in the south to Iceland in the north, encompassing the Seine estuary, Wadden Sea, a range of coastal, estuarine and offshore sites in the North Sea and one site in the Baltic (Table 1). The two coastal and two offshore sites on Iceland were included as reference sites.

The matrices chosen for ICON were sediment, haddock (Melanogrammus aeglefinus), dab (Limanda limanda), flounder (Platichthys flesus), red mullet (Mullus barbatus), gastropod (Nucella lapillus) and mussels (Mytilus edulis or M. galloprovincialis) (cf. Hylland et al., this issue-a). The chemical analyses performed in ICON were for PAHs, PCBs, Cd, $\mathrm{Hg}$ and $\mathrm{Pb}$ (Robinson et al., this issue). The biological responses included for fish were (exposure indicators): red blood cell micronucleus frequency, genotoxicity (comet assay), cytochrome P4501A activity (EROD), bile PAH metabolites (by HPLC), plasma vitellogenin (VTG) and intersex, and (effect indicators): lysosomal membrane stability (LMS), acetylcholinesterase inhibition (AChE), bile PAH metabolites (by synchronous scanning fluorometry, SFF), DNA adduct concentration, external fish disease, hepatic neoplasms and liver histology. The two methods for PAH metabolite analyses can be converted one to the other, but only SSF data has been linked directly to adverse effects in experimental studies, hence the grouping in "exposure" and "effect". Effect responses for mussels were acetylcholinesterase inhibition (AChE), stress-on- 
145

146

147

148

149

150

151

152

153

154

155

156

157

158

159

160

161

162

163

164

165

166

167

168

169

170

171

172

173

174

175

176

stress (SoS), scope for growth (SfG), metallothionein (MT), histopathology (histo), lysosomal membrane stability (LMS), and for gastropods imposex (VDSI). The reader is referred to Davies \& Vethaak (2012) and the relevant chapters of that volume for more detail on background data and the motivation for selecting methods. The selection of methods follows on from discussions in the ICES working group on biological effects of contaminants (WGBEC) over the past two decades (see e.g. ICES, 2010). The original list of recommended methods were further refined by the ICES/OSPAR working group SGIMC (ICES, 2011), taking into account additional issues such as cost-benefit and availability of analytical techniques in different countries. The final selection largely corresponds to the methods chosen by HELCOM for the Baltic (CORESET) (Lehtonen et al., 2014). The data from the individual studies in ICON (reported in this special issue) were compiled and subjected to a five-step procedure, eventually resulting in an overall assessment of the sites included in ICON. The assessment strategy is transparent and, depending on the objectives of an assessment, it may be desirable to stop after steps two, three or four.

\section{Step 1: Assessment of monitoring data against BAC and EAC}

All measurements performed within ICON were compared with the relevant BAC and EAC for that specific endpoint and species and expressed as a colour depending on whether the value exceeded the BAC or EAC. Details of calculations can be found in Davies \& Vethaak (2012) and in Vethaak et al. (this volume -a). A red classification would indicate that the value was above EAC, blue indicated values below the BAC, while green indicated concentrations or effect responses between the BAC and EAC. The method for determining whether a response is in either category can be found in Vethaak et al. (this issue-a). For all biological responses it is possible to identify a level at which the investigated population would be classified as being exposed to contaminants, i.e. with values above the background assessment concentration (BAC), but for only some of the methods will there be data available that can link the response to e.g. increased mortality in some life stage of the same species at that concentration, providing the environmental assessment concentration (EAC). 
177 Step 2: Integration of determinants by matrix for a given site

178 For each of the matrices the results of the individual assessments were aggregated

179 into three main categories: contaminants, exposure indicators and effects indicators.

180 For sediment/water, passive sampling and bioassays were done for some sites (see

181 Vethaak et al., this issue-a). Exposure indicators are biological responses that are not

182 predictive of "significant" effects, i.e. exceeding EAC, and can hence only be blue or

183 green. It was found necessary to split the biological effects measurements into two

184 categories depending on whether an EAC was set for that specific response or not.

185 Otherwise aggregated information on the proportion of determinants exceeding the

186 separate AC would be incorrect. For simplicity, these categories have been termed

187 'exposure indicators' (where an EAC has not been set) and 'effects indicators' where

188 an EAC (equivalent to significant pollution effect) has been set for the measurement.

189

190 In future projects with aggregation/integration of the above indicators across

191 matrices for a specific site, bioassays will be considered 'effects indicators' as EACs

192 become available. It will be possible to include data from passive sampling and in

193 vitro bioassays in both the water and sediment components in the framework

194 whenever assessment criteria become available.

196 The integration by matrix and category of determinant are expressed by three- or

197 four-coloured bars showing the proportions of determinants that exceed the BAC

198 and EAC. To indicate a lack of results for core methods or lack of data, grey has been

199 used. Each method for contaminant, effect or exposure assessment carries the same

200 weight, within matrix, in the integration. All determinants carry the same weight in

201 the assessment as they are perceived to have equivalent significance. That is to say

202 all determinants either represent a contaminant concentration or effect that is

203 either above or below background (BAC), or likely to cause (contaminant EAC) or be

204 indicative of (effect EAC) significant detrimental effects to individuals or

205 populations of marine organisms. 


\section{Step 3: Integration of matrices for a site assessment}

208 In order to express the results of assessment for any particular site, assessments

209 were aggregated across matrices and expressed by determinant category. To

210 achieve this, results from passive sampling from sediment and water categories

211 were integrated into the contaminant indicator graphic and bioassays and

212 gastropod intersex/intersex integrated into 'effects indicators'. Thus the outcome of

213 assessment of all determinants from all matrices can be expressed for a whole site.

214 Practically, the process adopted is to sum the percentages of each colour in, say, the

215 "contaminants" columns for each matrix, and then to scale the sums to a total of $216100 \%$.

218 For some assessments, this will be the highest level of aggregation required.

219 However, for assessments covering larger geographical areas where assessments

220 need to be undertaken across multiple sites, a further level of integration is required 221 (steps 4 and 5).

223 For transparency, each determinant group is labelled with the matrices from which

224 it is comprised. Thus it can quickly be determined whether the site assessment is

225 comprised of all or just a sub-set of the monitoring matrices.

227 Step 4: Regional assessment across multiple sites

228 A regional assessment can be done at different levels, i.e. aggregation of data at the 229 sub-regional, regional and national levels, in different ways to express both the 230 overall assessment of proportion of determinants (across all matrices) exceeding

231 both assessment thresholds (BAC/EAC) and by determinant for the region, showing 232 the proportion of sites assessed in the region that exceed the thresholds. Both 233 approaches show the overall proportion of determinant/site that exceeds the 234 threshold for each method. 


\section{ACCEPTED MANUSCRIPT}

236 Step 5: Overall assessment

237 The assessment by region can be aggregated further into a single schematic showing

238 the proportion all determinants across all sites that exceed BAC and EAC. This can

239 be used for the purposes of an overall assessment. The overall assessment can be

240 easily "unpacked" through the steps above to determine which sites and

241 determinants (effects types or contaminants) are contributing to, for example, the

242 proportion of red (greater than EAC) data, and thereby potentially leading to failure

243 to achieve the desired status for a region.

244

245 The assessment criteria for fish were grouped in three categories: concentrations of

246 selected contaminants, biomarkers of exposure (e.g. PAH metabolites and

247 cytochrome P4501A (EROD) activity) and biomarkers of effect (e.g. DNA damage,

248 fish disease). For each category the response at each location was then scored. 
Results

251 Assessments were performed by matrix (sediment, mussels, gastropods and fish), by 252 site and by region.

\section{Assessment results by matrix}

255 Contaminant concentrations measured did not exceed EAC values at any of the

256 offshore sites for sediments, yet at two of these sites (Iceland SE and Firth of Forth

257 offshore) sediment bioassay results exceeded EAC values, suggesting effects may be

258 being caused by contaminants not measured in sediment samples (Figure 1). Iceland

259 SE is adjacent to areas with high volcanic activity, which could result in elevated

260 concentrations of e.g. metals not analysed for. At inshore sites, concentrations of the

261 trace metals mercury and lead exceeded EAC values at the Wadden Sea site, the

262 Baltic Sea site and the Cartegena site in Spain, while mercury also exceeded EAC

263 values in the Seine estuary and the Firth of Firth, where PAH concentrations also

264 exceeded EAC. In the Wadden Sea, sediment bioassay results exceeded EACs,

265 indicating significant effects, presumably resulting from the high trace metal

266 concentrations recorded.

268 The mussel data assessment for Bjarnarhöfn (Iceland) and Palos Cape (SE Spain)

269 showed good relationship between chemical analytical results and biological

270 responses, with contaminant concentrations generally below BAC and little

271 biological effects (Figure 2). The results also showed a response of the mussels that

272 corresponded with the less contaminated station in Le Moulard (France) and the

273 more contaminated site in Le Havre (France), both in the Seine estuary. At one site

274 (Cartagena, SE Spain) there were elevated lead concentrations in the mussels, which

275 did not appear to result in biological effects. In contrast, a high stress response

276 (LMS) was observed at two sites (Firth of Forth in Scotland, Wadden Sea in the

277 Netherlands) where concentrations of the measured contaminants were below EAC

278 thresholds, suggesting alternative environmental stressors (not measured here) as

279 the cause of the response. More focused monitoring would be required to determine

280 the cause of the effects observed at those two sites. 
282

283

284

285

286

287

288

289

290

291

292

293

294

295

296

297

298

299

300

301

302

303

304

305

306

307

308

309

310

311

312

313

The imposex response of gastropods to environmental concentrations of organotins has been integrated in the scheme by incorporating results from adjacent shoreline populations (Figure 3). Only a single site (Le Havre in the Seine estuary) had a level of imposex of concern, above EAC.

The fish species included in the assessment were dab (LL), flounder (PF), haddock (MA) and red mullet (MB). Two of the species were found at some sites, e.g. dab and haddock in the Firth of Forth and the two Iceland sites and dab and flounder in the Seine estuary and the Baltic site (Figure 4). Concentrations of PCBs in dab, flounder and haddock exceeded EACs at some sites and fish at all sites except red mullet at Cartagena had elevated concentrations of $\mathrm{Cd}$. Furthermore, there was evidence of exposure of dab, flounder and haddock to PAHs at many sites, including Hvassahraun, Firth of Forth, German Bight, Wadden Sea, Seine sites and the Baltic site. There was good correspondence between results for the two methods used to quantify PAH metabolites, but no clear relationship between the elevated PAH metabolite concentrations at many locations and responses such as EROD and measures of genotoxicity (comet, DNA adducts). There were however values above EAC for both LMS and AChE at three sites, including Ekofisk, Dogger Bank and the Baltic site (all dab), and for one of them at Iceland (dab), Firth of Forth (dab), the Seine estuary (flounder) and the Baltic (flounder). Histology also suggested a range of sites were somewhat affected, i.e. dab at both Iceland sites, dab at Ekofisk, flounder at all Firth of Forth sites, dab at Firth of Forth, Dogger Bank and the German Bight.

\section{Assessment by site}

To allow region-wide assessments, data are combined by matrix and site. Such an assessment could include selected regions, e.g. Iceland, North Sea coastal and offshore, the Baltic and the Mediterranean. Figures are only shown for North Sea offshore to demonstrate what such an assessment may look like. Sites at Iceland included both coastal (Bjarnarhöfn, Hvassahraun) and offshore (Iceland SE, Iceland SW) locations. All determinants for the coastal sites were below EAC, whereas contaminants (PCB in haddock liver) and effects (AChE and DNA adducts in fish and 
314 bioassays of whole sediments) were above EAC for one or more of the two offshore

315 sites sampled. Most of the exposure responses were at or below background levels.

316 Both contaminants and effects were above EAC at some coastal sites in the North

317 Sea. Although coastal North Sea sites comprised the greatest data contribution to

318 the overall assessment, there were biological responses lacking, particularly for

319 exposure. Contaminant concentrations were largely below EAC levels in North Sea

320 offshore sites, except for PCBs in fish liver at Firth of Forth and German Bight

321 (Figure 5). At most sites there was evidence of exposure of fish to genotoxic

322 compounds. At the sites Ekofisk, Firth of Forth and Dogger Bank there were

323 significant levels (>EAC) of toxicant-induced physiological stress. At the single site

324 surveyed in the Baltic there was evidence of contamination above background levels

325 for PAH and heavy metals (Cd) with some heavy metals ( $\mathrm{Pb}, \mathrm{Hg}$ ) exceeding EAC

326 thresholds in sediment and PCBs exceeding EAC in dab livers. Dab was found to be

327 exposed to PAH, and both flounder and dab showed significant effects through LMS

328 (and AChE for flounder) effects indicators.

\section{Regional assessments}

331 Results of the assessments conducted above can be further aggregated into regional assessments by representing the proportion of determinant/matrix/site in each assessment category (blue, green, red). This can be visualised for contaminants, exposure and effects indicators as in Figure 6 or by combining the three in Figure 7.

336 For an area or region, Figure 7 shows that we have a simple aggregated assessment for

337 all matrices, determinants and sites in a region with the relative proportion of all

338 observations exceeding BAC and EAC. When considering suitable environmental targets

339 for contaminants and their effects and the wording of Descriptor 8 in the Marine

340 Strategy Framework Directive (MSFD), Good Environmental Status might be taken to

341 mean that concentrations of contaminants and measurements of their effects should

342 always be less than EAC. It should be borne in mind that when very large numbers of

343 observations are made there is always the possibility that outliers are present and it

344 would not be reasonable in such circumstances to have a 100\% compliance target (or

345 "one out all out"). Therefore SGIMC (ICES, 2011) proposed a pragmatic approach that 
$34695 \%$ of measurements should be less than EAC (allowing for a 5\% error rate). This 347 target is represented as a horizontal red line in Figure 7. 


\section{Discussion}

349 The assessment of the results from the ICON project shows that the framework provides a good and transparent reporting tool that makes it possible to present complex environmental monitoring datasets on contaminants concentrations and biological responses across multiple matrices, sites and seas. The key to the assessment is the development of the method- and species-specific criteria, which allows for the setting of thresholds of assumed equal significance for contaminants, exposure indicators and effect indicators, eventually allowing the different data types to be combined in a common indicator (cf. Vethaak et al., this issue-a). The flexibility and transparency is more extensive than frameworks proposed earlier, not least because contaminant concentrations and biological responses could be combined in a final assessment of environmental status. In addition, the ICON sampling campaign in European coastal and offshore areas provided a large dataset that resulted in a comprehensive and comparative evaluation of the state of selected

362 European coastal and offshore marine areas.

The core methods included in the scheme were selected as the minimum set of contaminants and biological effects techniques that would need to be applied in order to determine whether contaminants are impacting on 'ecosystem health'. They achieve this by covering the main contaminant groups likely to cause such effects and that may be routinely monitored, as well as covering the main toxicity endpoints that are reasonably measurable in sentinel species, i.e. general toxicant stress, neurotoxicity, genotoxicity (Hylland et al., this issue-b), carcinogenicity (Lang et al., this issue-b), endocrine disruption (Burgeot et al., this issue), energetic costs

372 (Martinez-Gomez et al., this issue-a) and mortality, as well as biomarkers of 373 exposure to groups of compounds likely to have such effects. This core set of 374 methods is not identical to, but similar to those suggested by under HELCOM 375 (Lehtonen et al., 2014), but more extensive than methods suggested in e.g. Giltrap et 376 al. (2013) and Hagger et al. (2008). Sediment bioassays are not mandatory in the 377 OSPAR framework, but should comprise more than one method (as reported here). 378 Sediment toxicity was addressed using different methods in Vethaak et al. (this issue $379-b)$. 
There are environmental factors that may modulate biological responses, e.g. season. Data used to derive BAC and EAC were from studies where ICES guidelines for sampling have been adhered to, i.e. sampling outside the reproductive period. Criteria have been developed for selected species using hundreds and thousands of analyses as a basis, but there is an underlying assumption in this strategy that a species will respond to contaminant exposure in a similar fashion throughout its geographical range, all else being equal.

The biological responses selected for the framework comprise a range of methods that are sensitive to contaminant stress, including some that are specific to important contaminant groups and some that provide responses to a wide range of substances, including cumulative effects and effects from chemicals not directly monitored for. The integrated nature of the approach also identified instances where high concentrations of contaminants of concern were recorded, but where effects were not detected at a significant level. In these instances, contaminant availability may be limited and concentrations of limited concern as a result. In this case, the lack of effects in the assessment will down-weigh the importance of the contaminant result in an overall assessment. If the 95\% target were to be used as a regional indicator of MSFD GES, Iceland and offshore North Sea would achieve the target using the ICON dataset, but inshore North Sea, Baltic and Spanish Mediterranean regions would fail.

Through applying the integrated assessment framework to the ICON dataset, several issues were identified that will need to be considered or spawn further research to improve the robustness of the framework. Because the assessment approach largely aggregates the results of applying thresholds to monitoring data at various levels of organisation and spatial scales, all data are treated equally in the assessment process and missing data will necessarily introduce less robustness into the overall assessment. Similarly, the introduction of additional data, for example from multiple matrices of the same type, e.g. multiple species of fish at the same site, can skew the assessment result. The ICON project has demonstrated that even on the scale of a large project with more than 20 partner institutions, data are likely to be missing from an assessment. In the current report, this has been dealt with by the use of 
'grey' in the figures, so that the uncertainty of an assessment can be identified. It is further recommended that a 'robustness indicator' be developed in order to be able to quantify the quality of site assessments (see Martinez-Gomez et al., this volume b). Such an indicator would be based on the relevance and completeness of the range of determinants comprising an assessment. Finally, the outcome of any integrated assessment has the potential to be strongly influenced by the selection of sites for the programme. At present there are no guidelines recommending a minimum number of sampling sites per region, appropriate statistical power for monitoring using this approach or how to account for hotspot or inshore sites in a wider scale regional assessment. Those are issues that need to be addressed to ascertain relevant and efficient marine monitoring in the future.

\section{Conclusions}

The ICON project has provided one of the most comprehensive integrated monitoring datasets of its kind and was found to be suitable for assessment using the framework developed within ICES and OSPAR. The approach is considered suitable for the determination of GES for Descriptor 8 under the MSFD.

The ICON project has shown that it is feasible to apply the OSPAR framework for integrated chemical and biological monitoring. The results show that Iceland has locations less impacted by contaminants than other locations in Europe, followed by offshore locations in the North Sea, with coastal locations being most clearly impacted.

The framework can be applied to datasets with missing data and determinants, but the validity of the assessment decreases with increasing missing data. Further guidance on minimal requirements for an integrated assessment and the development of a robustness indicator is suggested.

Assessment criteria for passive sampling techniques and in vitro bioassays need further development before they can be included in the integrated assessment framework. 
447 There is a need to evaluate some assumptions in the OSPAR framework, e.g. that

448 different populations of a species with a wide geographical coverage will respond

449 similarly to contaminant exposure.

450

451

452

\section{Acknowledgements}

453 The authors wish to acknowledge the work by colleagues in ICES and OSPAR working 454 group, i.e. WGBEC, WKIMON, SGIMC, as well as the cruise leaders, cruise participants 455 and crews of R/V Walther Herwig III (Germany), R/V Scotia, R/V Alba na Mara 456 (Scotland), R/V Gwen Drez (France) and R/V Endeavour (UK). The French participation 457 was funded by IFREMER and ONEMA. 


\section{Literature references}

Adams, S.M., Brown, A.M., Goede, R.W., 1993. A quantitative Health Assessment Index for rapid evaluation of fish condition in the field. Transactions of the American Fisheries Society, 122, 6373.

Allen, Y., Scott, A. P., Matthiessen, P., Haworth, S., Thain, J. E., Feist, S. 1999. Survey of estrogenic activity in United Kingdom estuarine and coastal waters and its effects on gonadal development of the flounder Platichthys flesus. Environmental Toxicology and Chemistry, 18, 1791-1800. Bocquene, G., Galgani, F., Burgeot, T., Le-Dean, L., Truquet, P., 1993. Acetylcholinesterase levels in marine organisms along French coasts. Marine Pollution Bulletin, 26, 101-106. Broeg, K., von Westernhagen, H., Zander, S., Körting, W., Koehler, A., 2005. The biological assessment index (BAI) a concept for the quantification of effects of marine pollution by an integrated biomarker approach. Marine Pollution Bulletin, 50, 495-503.

473 Bourlat, S.J., Borja, A., Gilbert, J., Taylor, M.I., Davies, N., Weisberg, S.B., Griffith, J.F., Lettieri, T., 474 Field, D., Benzie, J., Glöckner, F.O., Rodríguez-Ezpeleta, N., Faith, D.P., Bean, T.P., Obst, M., 2013. 475 Genomics in marine monitoring: New opportunities for assessing marine health status. Marine 476 Pollution Bulletin, 74, 19-31.

477 Carney Almroth, B., Hultman, M., Wassmur, B., Sturve, J., Is oxidative stress evident in dab 478 (Limanda limanda) in the North Sea? (this issue)

479 Chapman, P.M., McDonald, B.G., Lawrence, G.S., 2002. Weight-of-evidence issues and frameworks 480 for sediment quality (and other) assessments. Human and Ecological Risk Assessment 8, 14894811515.

482 Dagnino, A., Allen, J.I., Moore, M.N., Broeg, K., Canesi, L., Viarengo, A., 2007. Development of an 483 expert system for the integration of biomarker responses in mussels into an animal health index. 484 Biomarkers, 12, 155-172.

485 Davies, I.M., Vethaak, A.D. (Eds.), 2012. Integrated monitoring of chemicals and their effects. ICES 486 Cooperative Research Report 315, 227 pp.

487 Devin, S., Burgeot, T., Giamberini, L., Minguez, L., Pain-Devin, S., 2014. The integrated biomarker 488 response revisited: optimization to avoid misuse. Environmental Science And Pollution 489 Research, 21, 2448-2454. 
490 Giltrap, M., Ronan, J., Hardenberg, S., Parkes, G., McHugh, B., McGovern, E., Wilson, J.G., 2013.

491 Assessment of biomarkers in Mytilus edulis to determine good environmental status for

492 implementation of MSFD in Ireland. Marine Pollution Bulletin 71, 240-249.

493 Hagger, J.A., Jones, M.B., Lowe, D., Leonard, D.R.P., Owen, R., Galloway, T.S., 2008. Application of

494 biomarkers for improving risk assessments of chemicals under the Water Framework Directive:

495 A case study. Marine Pollution Bulletin, 56, 1111-1118.

496 Hylland, K., Beyer, J., Berntssen, M., Klungsøyr, J., Lang, T., Balk, L. 2006. May persistent organic 497 pollutants affect fish populations in the North Sea? Journal of Toxicology and Environmental 498 Health, Part A, 69, 125-138.

499 Hylland, K., Gubbins, M.J., Robinson, C., Burgeot, T., Martínez-Gómez, C., Lang, T., Svavarsson, J., 500 Thain, J.E., Vethaak AD. Integrated chemical and biological assessment of contaminant impacts in 501 selected European coastal and offshore marine areas (this issue-a)

502 Hylland, K., Ruus, A., Grung, M., Green, N., 2009. Relationships between physiology, tissue 503 contaminants and biomarker responses in Atlantic cod (Gadus morhua L.). Journal of Toxicology 504 and Environmental Health, Part A, 72, 226-233.

505 Hylland, K., Skei, B.B., Gubbins, M.J., Lang, T., Brunborg, G., Le Goff, J., Burgeot, T., Genotoxicity in 506 dab (Limanda limanda) and haddock (Melanogrammus aeglefinus) from European seas (this 507 issue-b)

508 Hylland, K., Tollefsen, K.-E., Ruus, A., Jonsson, G., Sundt, R.C., Sanni, S., Utvik, T.I.R., Johnsen, S., 509 Nilssen, I., Pinturier, L., 2008. Water column monitoring near oil installations in the North Sea 510 2001-2004. Marine Pollution Bulletin, 56, 414-429.

511 ICES, 2011. Report of the Study Group on Integrated Monitoring of Contaminants and Biological 512 Effects (SGIMC), 14-18 March 2011, Copenhagen, Denmark. ICES CM 2011/ACOM:30. 265 pp.

513 Kammann, U., Akcha, F., Budzinski, H., Burgeot, T., Gubbins, M.J., Lang, T., Le Menach, K., Vethaak, 514 A.D., Hylland, K. PAH metabolites in fish bile: from the Seine Estuary to Iceland (this issue)

515 Lang, T., Feist, S.W., Stentiford, G.D., Bignell, J., Vethaak, A.D., Wosniok, W. Diseases of dab

516 (Limanda limanda): analysis and assessment of data on externally visible diseases, macroscopic 517 liver neoplasms and liver histopathology at offshore sites in the North Sea, Baltic Sea and off 518 Iceland (this issue-a)

519 Lang, T., Kruse, R., Haarich, M., Wosniok, W. Methylmercury in dab (Limanda limanda) from the 520 North Sea, Baltic Sea and Icelandic waters: relationship to host-specific variables (this issue-b) 
521 Lyons, B., Thain, JE, Stentiford, GD, Hylland, K, Davies, I, Vethaak, AD. 2010. Using biological

522 effects tools to define Good Environmental Status under the European Union Marine Strategy

523 Framework Directive. Marine Pollution Bulletin, 60, 1647-1651.

524 Lyons B.P., Bignell, J.P., Stentiford, G.D., Bolam, T., Rumney, H.S., Bersuder, P., Barber, J., Askem,

525 C.W., Maes T., Thain, J.E. Determining Good Environmental Status under the Marine Strategy

526 Framework Directive: case study for descriptor 8 (chemical contaminants) (this issue)

527 Marigómez, I., Garmendia, L., Soto, M., Orbea, A., Izagirre, U., Cajaraville, M.P., 2013. Marine

528 ecosystem health status assessment through integrative biomarker indices: a comparative study

529 after the Prestige oil spill "Mussel Watch". Ecotoxicology, 22, 486-505.

530 Martínez-Gómez C., Burgeot T., Robinson, C.D., Gubbins, M.J., Halldorsson, H.P. Albentosa, M.,

531 Bignell J.P., Hylland, K., Vethaak A.D. Lysosomal membrane stability and Stress on Stress in

532 mussels as common Pan-European contaminant-related biomarkers (this issue-a)

533 Martínez-Gómez C., Fernández B., Robinson, C.D., Campillo J.A., León V.M., Benedicto J., Hylland,

534 K., Vethaak A.D. Assessing the good environmental status (GES) of the Cartagena coastal zone (W

535 Mediterranean) using an integrated framework of chemical and biological effect data: a practical

536 case study (this issue-b)

537 OSPAR, 2008. Draft Agreement on CEMP Assessment Criteria for the QSR 2010, , MON 09/8/1/6

538 Add.1. OSPAR Commission, London.

539 OSPAR, 2010. Quality Status Report 2010. OSPAR Commission, London, 176 pp.

540 Robinson, C.D., Webster, L., Martínez-Gómez, C., Burgeot, T., Gubbins, M.J., Thain, J.E., Vethaak,

541 A.D., McIntosh, A.D., Hylland, K. Assessment of contaminant concentrations in sediments, fish

542 and mussels sampled from the North Atlantic and European regional seas within the ICON

543 project (this issue)

544 Sandstrom, O., Larsson, A., Andersson, J., Appelberg, M., Bignert, A., Ek, H., Forlin, L., Olsson, M.,

545 2005. Three decades of Swedish experience demonstrates the need for integrated long-term

546 monitoring of fish in marine coastal areas. Water Quality Research Journal of Canada, 40, 233-

547250.

548 Thain, J.E., Vethaak, A.D., Hylland, K., 2008. Contaminants in marine ecosystems: developing an

549 integrated indicator framework using biological effects techniques. ICES Journal of Marine

550 Science, 65, 1508-1514.

551 Tornero, V., d' Alcalà, M.R., 2014. Contamination by hazardous substances in the Gulf of Naples

552 and nearby coastal areas: A review of sources, environmental levels and potential impacts in the

553 MSFD perspective. Science of the Total Environment 466, 820-840. 
554 Vethaak, A.D., Davies, I.M., Thain, J.E., Gubbins, M.J., Martínez-Gómez, C., Robinson, C.D., Moffat,

555 C.F., Burgeot, Maes, Wosniok, Giltrap, M., Lang, T., Strand, J., Hylland, K. Integrated indicator

556 framework and methodology for monitoring and assessment of hazardous substances and their

557 effects in the marine environment (this issue-a)

558 Vethaak, A.D., Hamers, T., Martínez-Gómez, C., Kamstra, J.H., de Weert, J., Leonards, P., Smedes, F.

559 Toxicity profiling of marine surface sediments: a case study using rapid screening bioassays of

560 exhaustive total extracts, elutriates and passive sampler extracts (this issue-b)

561 Vethaak, A. D., Jol, J. G., Martínez-Gómez, C., 2011. Effects of cumulative stress on fish health near

562 freshwater outlet sluices into the sea: a case study (1988-2005) with evidence for a contributing

563 role of chemical contaminants. Integrated environmental assessment and management, 7, 445-

564458.

565 
566

567

568

569

570

571

572

573

574

575

576

577

578

579

580

581

582

583

584

585

586

587

588

589

590

591

592

593

594 Figure 7. Integrated assessment for each of the five areas. From left: Iceland (4 sites),

595 coastal North Sea (10 sites), offshore North Sea (5 sites), German Baltic Sea (1 site) and

596 Spanish Mediterranean Sea (2 sites). Numbers indicate data for each category; red line = $59795 \%$ threshold.

598

\section{Figure captions}

Figure 1. Assessment of sediment data against BAC (background assessment criteria) and EAC (ecotoxicological assessment criteria); blue - below BAC, green - between BAC and EAC, red - above EAC, grey - data lacking; FoF = Firth of Forth.

Figure 2. Assessment of mussel data against BAC (background assessment criteria) and EAC (ecotoxicological assessment criteria); blue - below BAC, green - between BAC and EAC, red - above EAC; grey cells indicate core analyses not performed.

Figure 3. Assessment of imposex data (as VDSI) against BAC (background assessment criteria) and EAC (ecotoxicological assessment criteria); blue - below BAC, green between BAC and EAC, red - above EAC; grey cells indicate analyses not performed.

Figure 4. Assessment of contaminant concentrations (liver), exposure and effects in fish from Iceland, the North Sea, Baltic Sea, Seine estuary (two sites) and Mediterranean Sea; LL - dab, PF - flounder, MA - haddock, MB - red mullet; blue - below BAC, green between BAC and EAC, red - above EAC; grey cells indicate core analyses not performed; see Davies \& Vethaak (2012) and relevant chapters for individual methods.

Figure 5. Assessment of contaminants, exposure and effects for the indicated locations in the North Sea (offshore); grey cells indicate core analyses not performed.

Figure 6. Assessment of contaminants, exposure and effects for each of the five areas. From left: Iceland (4 sites), coastal North Sea (10 sites), offshore North Sea (5 sites), German Baltic Sea (1 site) and Spanish Mediterranean Sea (2 sites). Numbers indicate data for each category. 
Table 1. Locations and matrices sampled (revised from Hylland et al., this issue).

\begin{tabular}{|l|l|l|l|}
\hline Location & Type & Country & Matrices sampled \\
\hline Hvassahraun & Inshore & Iceland & Mussel, flounder \\
\hline Bjarnarhöfn & Inshore & Iceland & Mussel \\
\hline SE Iceland & Offshore & Iceland & Dab, haddock, sediment \\
\hline SW Iceland & Offshore & Iceland & Dab, haddock, sediment \\
\hline Egersund bank & Offshore & Norway & Dab, haddock, sediment \\
\hline Ekofisk & Offshore & Norway & Dab, haddock, sediment \\
\hline Firth of Forth - Alloa & Estuary & Scotland & Flounder \\
\hline Firth of Forth - Blackness & Estuary & Scotland & Mussel, flounder, sediment \\
\hline Firth of Forth - St Andrews Bay & Inshore & Scotland & Flounder \\
\hline Firth of Forth & Offshore & Scotland & Dab, haddock, sediment \\
\hline Dogger Bank & Offshore & Germany & Dab, sediment \\
\hline German Bight & Offshore & Germany & Dab, sediment \\
\hline Baltic Sea & Inshore & Germany & Flounder, dab, sediment \\
\hline Wadden Sea & Inshore & Netherlands & Flounder, mussel, sediment \\
\hline Seine estuary & Estuary & France & Dab, flounder, mussel, sediment \\
\hline Seine bay & Inshore & France & Dab, flounder, mussel, sediment \\
\hline Cartagena & Inshore & Spain & Red mullet, mussel, sediment \\
\hline Cape Palos & Inshore & Spain & Mussel \\
\hline
\end{tabular}

*From coastal locations adjacent to the sampling point. 
Figure 1

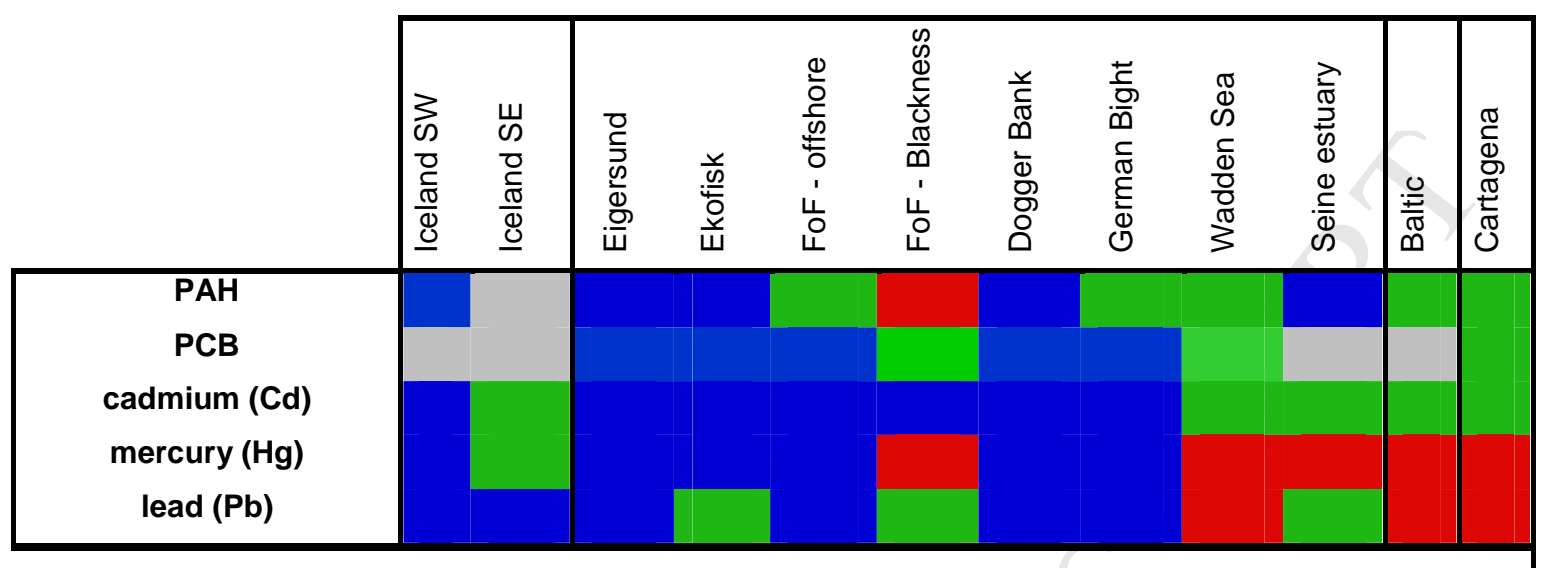

Sea urchin bioassay 
Figure 2.

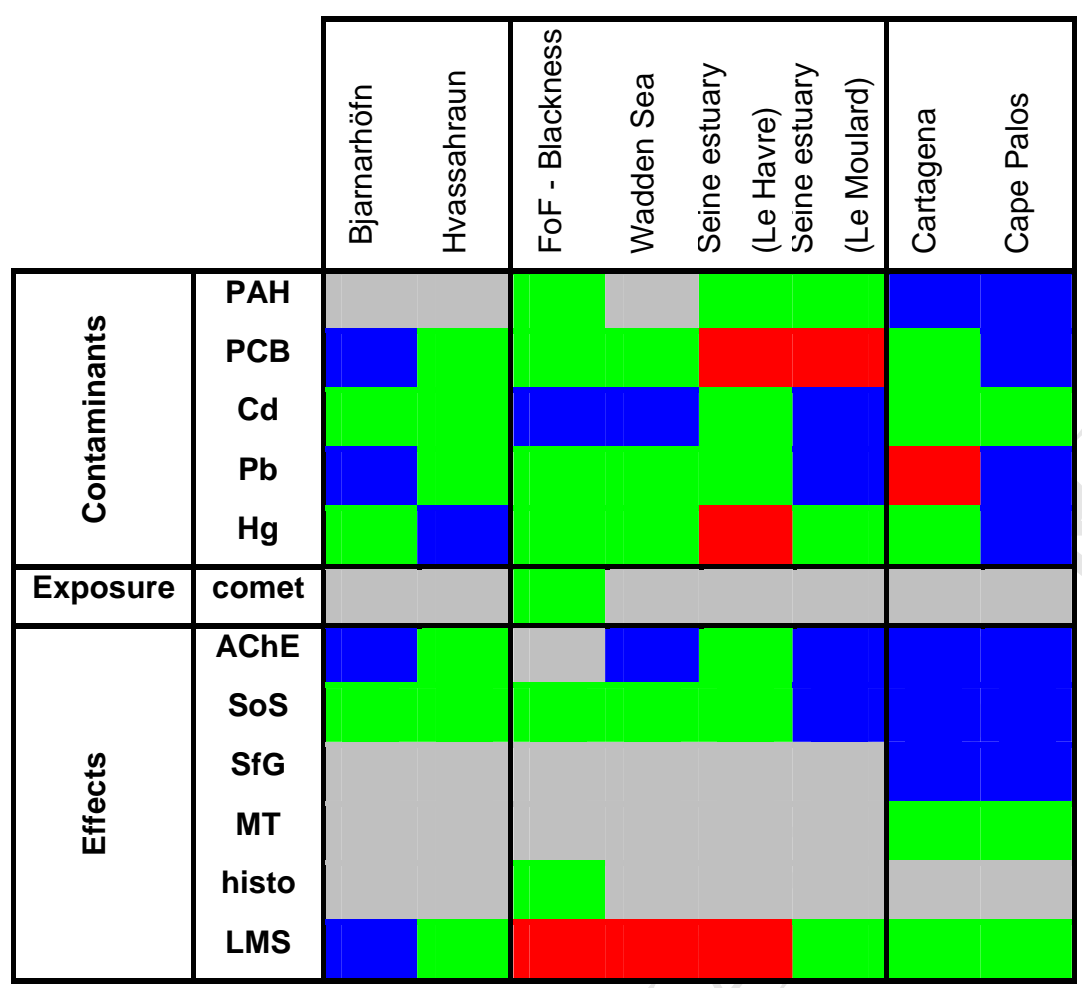


Figure 3.

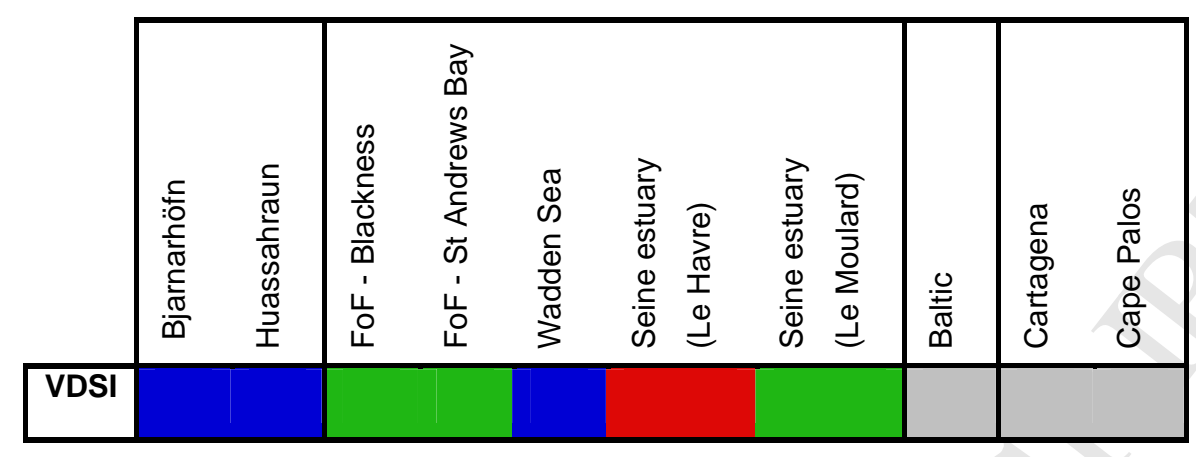


Figure 4.

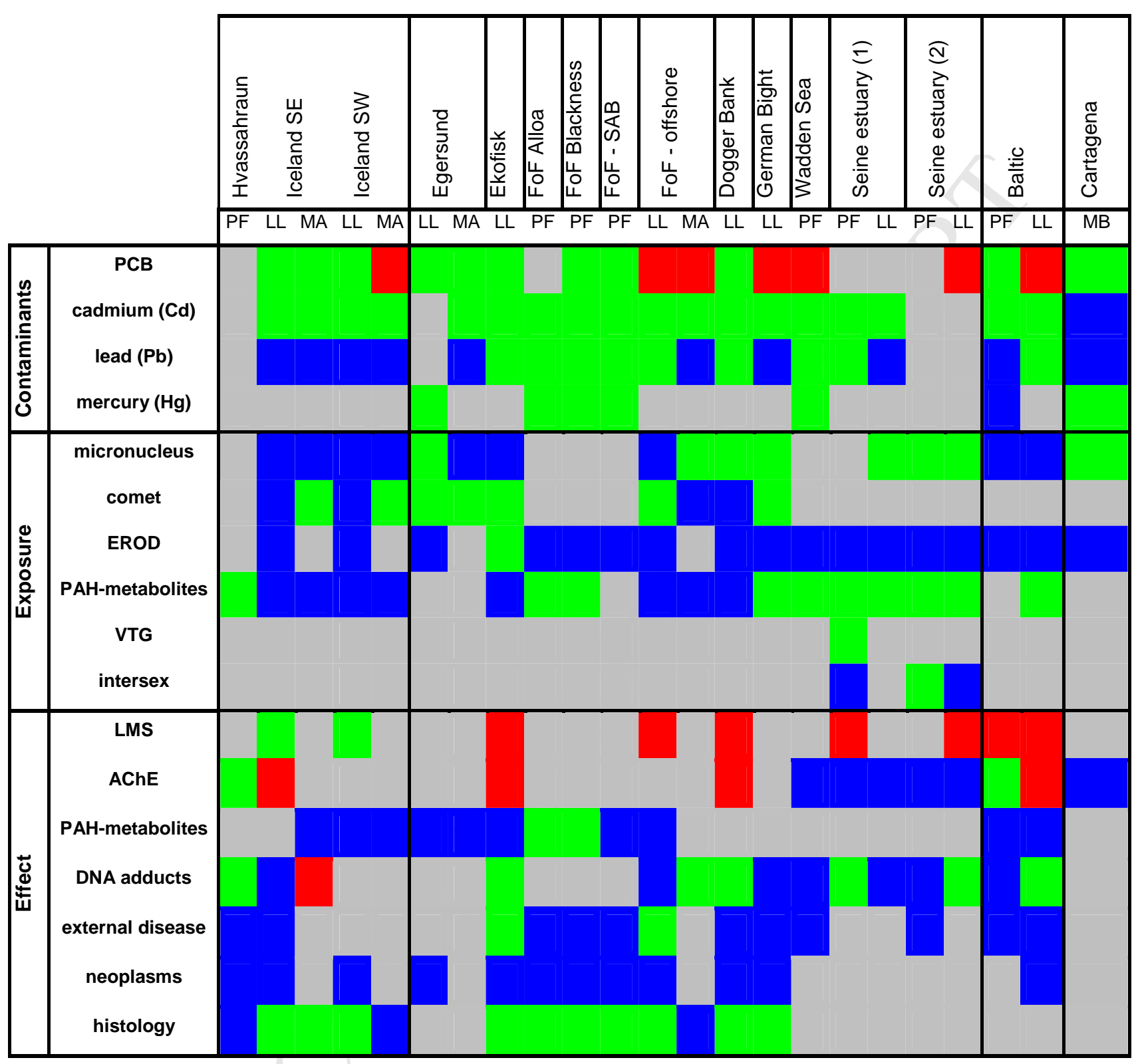


Figure 5

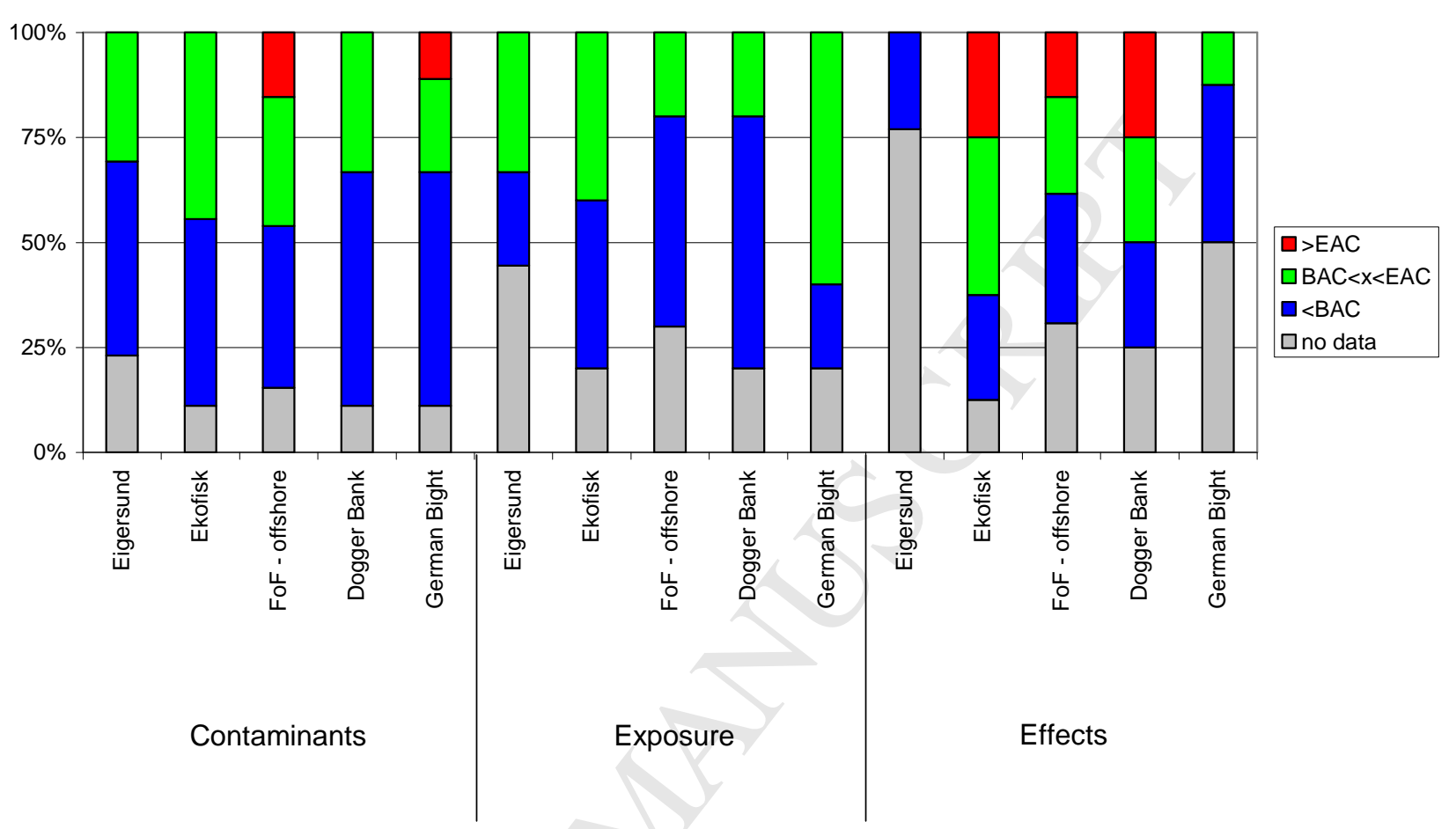


Figure 6.

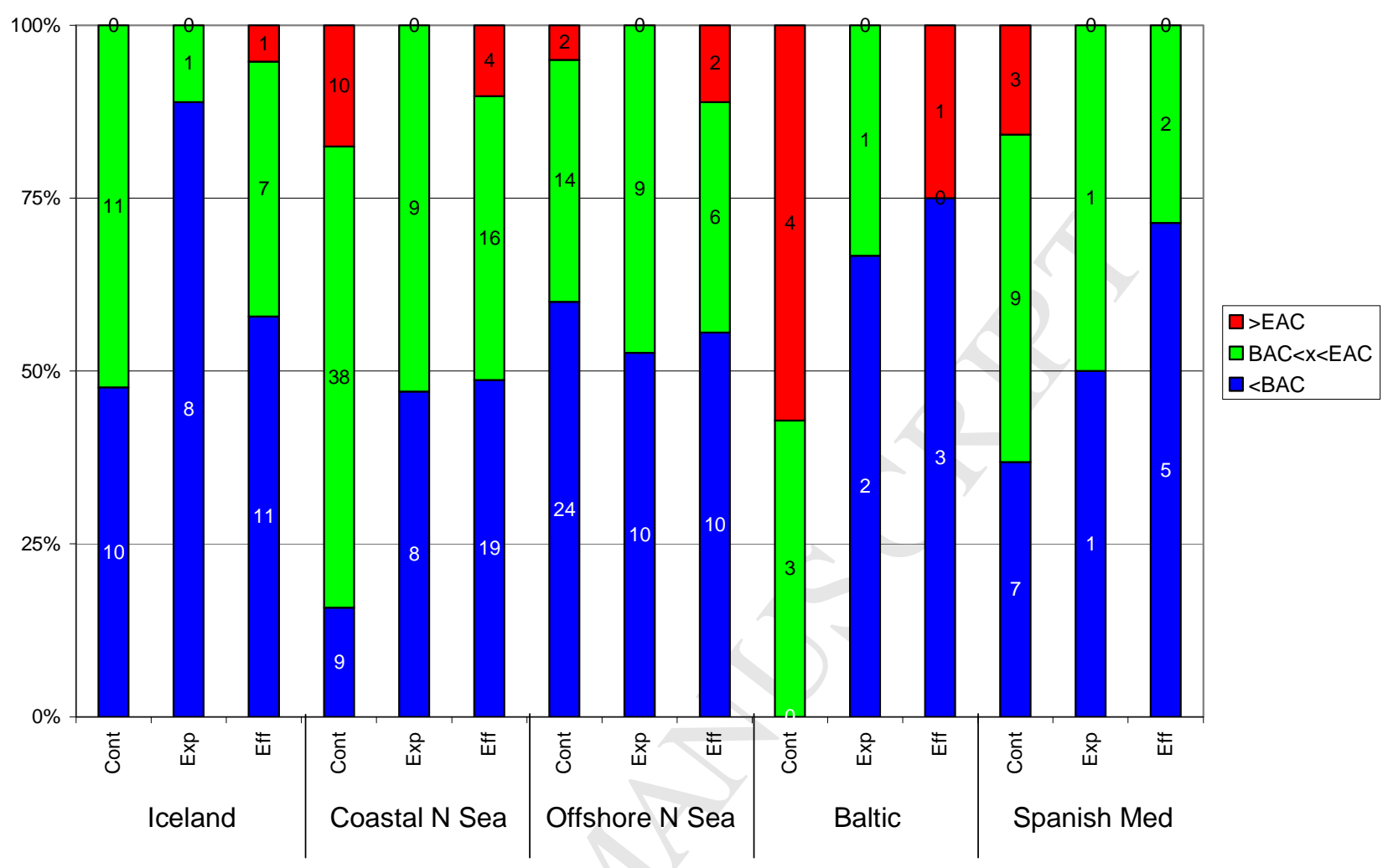


Figure 7.

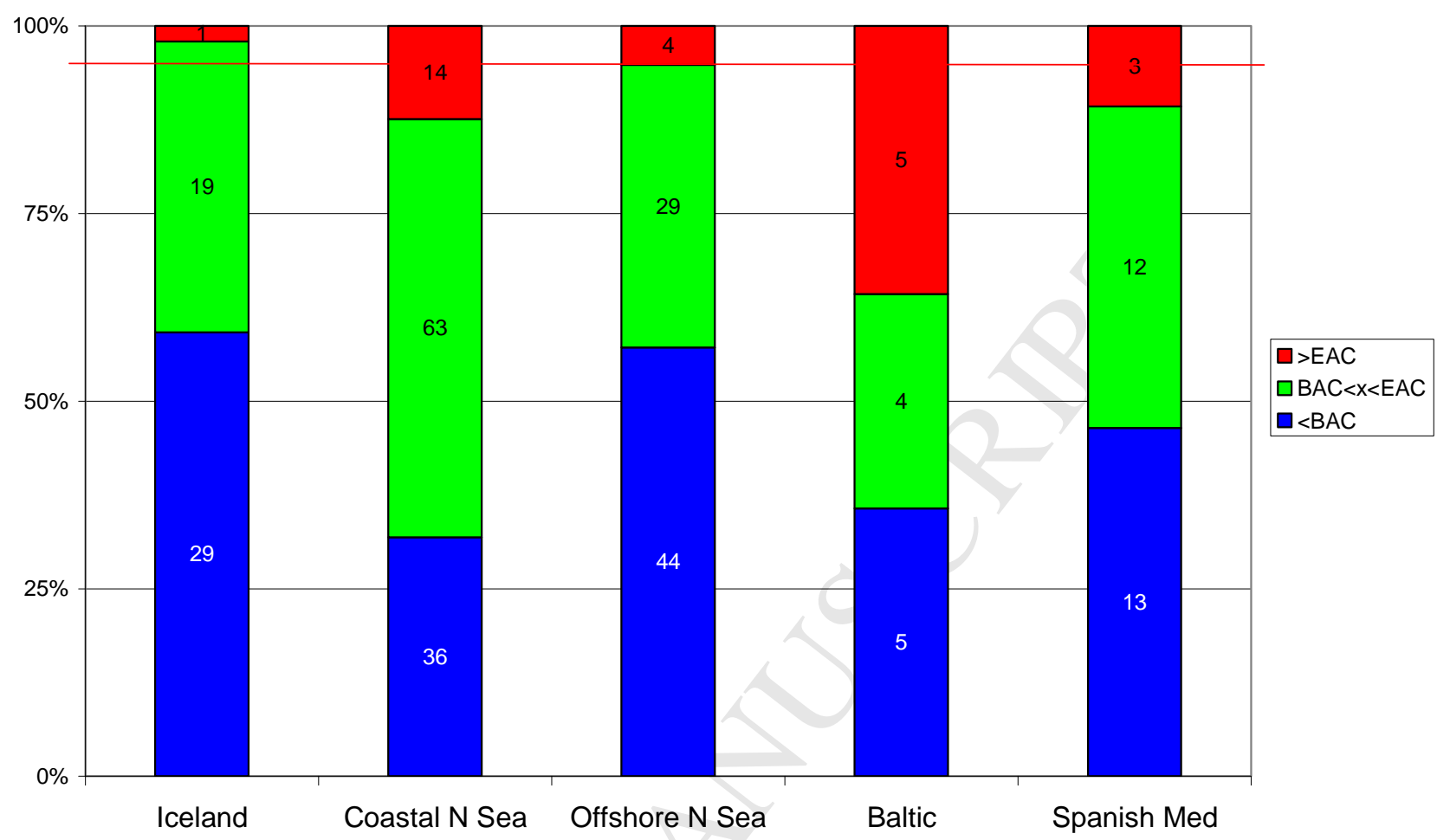


Highlights

- A framework for integrated assessment of contaminant impacts in coastal and offshore areas has been developed and demonstrated.

- The assessment clearly shows why it is necessary to include both chemical analyses and biological effects in an assessment of contaminant impacts.

- Only two of the areas, Iceland and offshore North Sea, would be classified as having "Good Environmental Status" should MSFD criteria be used. 